\title{
A Three-Section-Settlement Calculation Method for Composite Foundation Reinforced by Geogrid-Encased Stone Columns
}

\author{
Binhui Ma $\mathbb{D}^{1,2}$ Zhiyong Hu, ${ }^{1}$ Zhuo Li, ${ }^{1}$ Kai Cai, ${ }^{1}$ Minghua Zhao, ${ }^{3}$ Chengbin He, ${ }^{1}$ \\ Qiunan Chen, ${ }^{1,2}$ Bingchu Chen, ${ }^{1}$ and Xiaocheng Huang ${ }^{1,2}$ \\ ${ }^{1}$ School of Civil Engineering, Hunan University of Science and Technology, Xiangtan 411201, China \\ ${ }^{2}$ Hunan Provincial Key Laboratory of Geotechnical Engineering for Stability Control and Health Monitoring, \\ Hunan University of Science and Technology, Xiangtan 411201, China \\ ${ }^{3}$ School of Civil Engineering, Hunan University, Changsha 410082, China \\ Correspondence should be addressed to Binhui Ma; mbh@hnust.edu.cn
}

Received 20 February 2021; Revised 18 March 2021; Accepted 2 April 2021; Published 23 April 2021

Academic Editor: Rihong Cao

Copyright $\odot 2021$ Binhui Ma et al. This is an open access article distributed under the Creative Commons Attribution License, which permits unrestricted use, distribution, and reproduction in any medium, provided the original work is properly cited.

\begin{abstract}
The analysis of the bearing characteristics and deformation mechanism of composite foundation reinforced with geogrid-encased stone columns is presented in order to obtain its settlement calculation method. The settlement of composite foundation is divided into three sections which are the reinforced section, unreinforced section, and underlying stratum. Based on Hooke's law of space problem and the thoughts of the layer-wise summation method, the relative slip displacement between pile and soil of reinforced section without plastic zone is analyzed. The settlement of reinforced section is calculated by the layered iteration method based on the pile element model. The compatibility of vertical and radial deformations of unreinforced section is analyzed based on the pilesoil element model. The settlement of underlying stratum is still calculated by the layer-wise summation method. Finally, two engineering examples are analyzed and the results show that the settlement calculated by the presented method is close to the measured one. The method overcomes the defect that the calculated results by the other existing methods are more dangerous and it is more feasible and can be applied in engineering practice.
\end{abstract}

\section{Introduction}

Stone column has been widely used in soft clay improving engineering as a common reinforcement [1]. The bearing capacity of stone column mainly depends on the lateral restraint provided by the surrounding soil [2]. When the lateral restraint force is insufficient, the top part of the stone column body is prone to swelling, resulting in the reduction of its bearing capacity and the increase of settlement, which fails to achieve the expected effect of reinforcement [3]. In engineering practice, the treatment method of covering the geogrid encasement into stone column in the depth range of $2 \sim 3$ times of pile diameter is adopted to make use of the hoop effect of the geogrid encasement on the pile body to increase its lateral restraint force and limit the swelling deformation of the pile body, so as to improve the bearing capacity and reduce the settlement. This new type can be called composite foundation by geogrid-encased stone columns. Because of the effect of the geogrid encasement, the bearing capacity and deformation characteristics of the stone column have changed, so it is not appropriate to simply apply the existing settlement calculation method of the composite foundation to analyze the settlement of the composite foundation reinforced by geogrid-encased stone columns. Therefore, how to combine the characteristics of geogrid-encased stone columns and deeply discuss the settlement calculation method of that has an important theoretical significance for engineering design.

At present, the research methods of geogrid-encased stone columns are mostly laboratory tests, numerical simulation and field tests, etc. The research mainly focuses on the analysis of bearing capacity and stability. The bearing capacity of geogrid-encased stone columns is early analyzed by Zhou and Zhang [4] with the limit equilibrium theory. 
Chen et al. [5-7], respectively, derived the bearing capacity calculation formula of the top-reinforced stone column based on the expansion theory of circular hole, the slider balance method, and the upper limit analysis method. Based on the progress of limit equilibrium theory and considering the failure mode of geogrid-reinforced crushed stone pile, Zhao et al. [8,9] deduced the calculation formula of ultimate bearing capacity of single reinforced crushed stone pile. However, the research on settlement calculation of composite foundation reinforced by geogrid-encased stone columns is relatively few. Cao and Yang [10] divided geogrid-encased stone column into reinforced section, unreinforced plastic section, and unreinforced elastic section according to the relative slip between column and surrounding soil, established corresponding settlement analysis model according to the deformation characteristics of different sections, and obtained the settlement calculation method of geogrid-encased stone column composite foundation under flexible foundation. Wu and Chen [11] also divided the reinforcement into three sections and derived settlement formulas for each section based on elastic mechanics and pile-soil coordinated deformation. According to the observation and conclusion of numerical simulation results, Tan et al. [12] established the analytical solution of the ultimate bearing capacity of geogrid-encased stone column in soft clay. Esameldin and Zalihe [13] studied the bearing capacity of geogrid-encased stone column in different soft soils through laboratory experiments.

Although these research studies on the bearing deformation mechanism of the geogrid-encased stone column are fine, they are still with some limitations and shortcomings. For example, the friction of geogrid-encased stone column caused by relative slip of column and soil is too complicated to be considered. The lateral deformation of column decreases rapidly with depth, and there is not necessarily a plastic zone, so the assumption that there are three sections is not necessarily valid. In addition, from the calculation results, the theoretical value is less than the measured value, and the calculation is biased to the danger. Therefore, on the basis of previous research, the composite foundation reinforced by geogrid-encased stone column is divided into three sections, which are the reinforced section, unreinforced section, and underlying stratum. Based on Hooke's law of space problem and the thoughts of the layer-wise summation method, the deformation of stone column is calculated based on the pile element by the layer-iteration method, considering the relative slip of pile and soil without plastic zone. The pile-soil unit model is introduced for analysis according to the coordination of the vertical and radial deformations of pile and soil in the unreinforced section. The settlement of the underlying stratum is calculated by the layer-wise summation method, and then the settlement calculation method of the composite foundation is proposed.

\section{Deformation Mechanism Analysis}

Generally speaking, the settlement of composite foundation reinforced by geogrid-encased stone columns consists of cushion, reinforcement area, and underlying layer [1] (Figure 1).

Because the thickness of the cushion is generally smaller and the compaction degree is higher, the settlement deformation is basically completed in the construction stage, so it can be ignored. Therefore, the settlement $S$ of geogridencased stone column composite foundation can be regarded as the sum of the compression amount $S_{1}$ in the reinforcement area and the compression amount $S_{2}$ in the underlying strata, namely,

$$
S=S_{1}+S_{2} .
$$

According to the existing research results [9-11], the reinforcement area can be divided into reinforced section and unreinforced section according to whether the pile is wrapped by geogrid encasement, so $S_{1}$ can be expressed as

$$
S_{1}=S_{11}+S_{12} \text {. }
$$

In the formula, $S_{11}$ and $S_{12}$ are the compression amount of the stiffened segment and the nonstiffened segment, respectively. Thus, equation (1) can be rewritten as

$$
S=S_{11}+S_{12}+S_{2} \text {. }
$$

Formula (3) is the settlement calculation method of composite foundation reinforced by geogrid-encased stone column that is commonly used at present, in which the compression deformation of the underlying strata $S_{2}$ is solved by the traditional layered summation method. It can be seen from this that the key to the settlement calculation of composite foundation lies in the determination of compression deformation $S_{11}$ and $S_{12}$ in the reinforcement area.

2.1. Reinforced Section. As the pile body is wrapped by the grille sleeve, the integrity and deformation stiffness of the reinforced section are greatly improved, and a relatively clear pile-soil contact surface is formed by means of the grille. The deformation mechanism is similar to that of a flexible pile or semirigid pile. However, the pile body is composed of loose materials and has no cohesive force. Under the action of load, the stress concentration of the pile body produces ineligible swelling deformation. When the composite foundation bears a large load, there is a relative displacement or displacement trend at the pile-soil interface of the reinforced section, which leads to the existence of pile lateral friction at the pile-soil interface. In this paper, the pile element is used and the layered iterative method is used to calculate.

2.2. Unreinforced Section. Without the lateral restraint of geogrid, the stiffness of unreinforced section of stone column decreases obviously. There are vertical and radial deformations existing in the unreinforced section under the vertical load, especially the radial deformation is extremely obvious because of the sudden change of the stiffness of stone column at the junction of the reinforced and unreinforced section, which is also the reason for the bulging failure of the geogrid-encased stone columns [14]. Without 


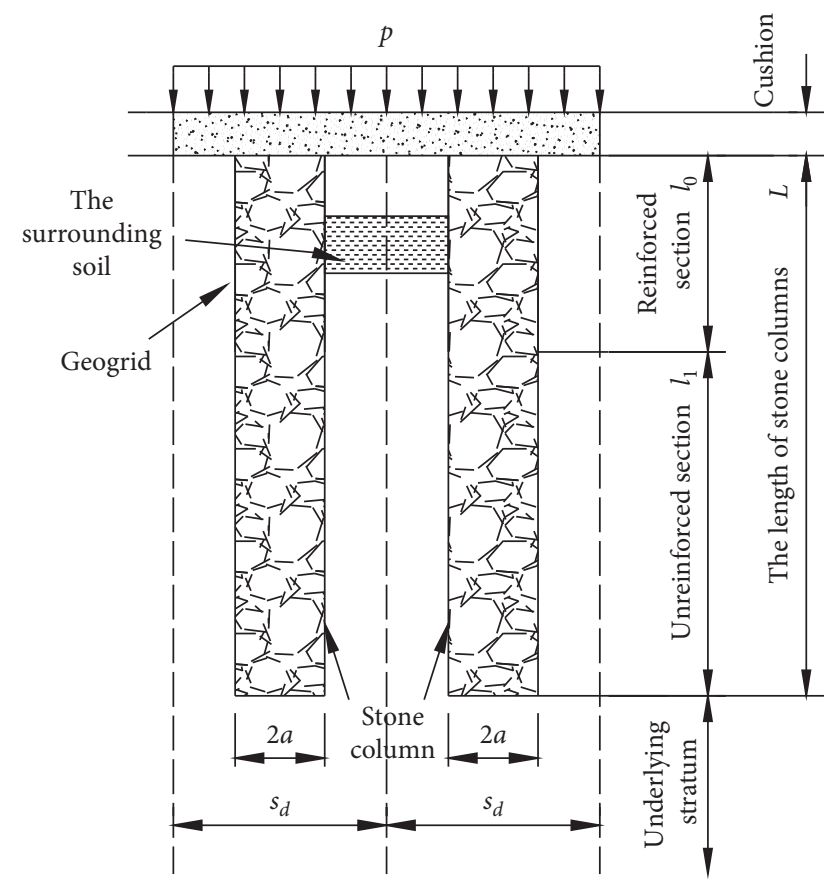

FIgURE 1: Composition of composite foundation reinforced by geogrid-encased stone columns.

geogrid encasement, stone columns are embedded into the surrounding soil, which makes the boundary between columns and soil very fuzzy, and the relative displacement small to be neglected. In addition, due to stress diffusion, the additional stress of the pile decreases sharply with depth, and its lateral deformation decreases correspondingly. Therefore, the bulging deformation of the whole unreinforced section is not uniform. However, considering the continuous and coordinated deformation characteristics of the pile-soil, the unreinforced section is analyzed by pile-soil element to simplify the calculation.

Therefore, the settlement analysis method of composite foundation reinforced by geogrid-encased stone column established in this paper must fully reflect the deformation mechanics mechanism of the reinforced section and the unreinforced section. Therefore, the settlement deformation of reinforced segment and unreinforced segment will be analyzed, respectively, on this basis.

\section{Compression Deformation Analysis}

3.1. The Basic Assumptions. In this paper, the research is mainly limited to the reinforced stone column formed by the two-way high-strength geogrid at the depth of $2 \sim 3$ times of the pile diameter below the top of the stone column, and to simplify the calculation, the following basic assumptions are made:

(a) The geogrid encasement has sufficient strength and stiffness and will not be plastic deformation or tension due to pile deformation

(b) The mesh hole of the geogrid encasement is smaller than the particle size of gravel, and the gravel particles are not allowed to bulge out from the sleeve (c) Under normal working conditions, the pile body and the soil around the pile can be linear elastomer

(d) Only the influence of additional stress on the compression deformation of pile body and soil around pile is considered, not the influence of dead weight

(e) Effect of pile-group is not considered in the composite foundation

(f) The microelement body of the selected segment is very small, and the volume change of the pile and soil element body can be ignored

The pile body and the unit body composed of soil around the pile within its influence range were taken as research objects for analysis, as shown in Figure 2 where $a$ is the radius of pile body and $b$ is the radius of pile and soil unit body, which can be obtained from the distance of pile body and the way of pile layout:

$$
d_{e}=c_{g} s_{d}=2 b,
$$

where $d_{e}$ is the diameter of the element body; $s_{d}$ is the center distance between piles; and $c_{g}$ is the influence coefficient of pile layout (for plum-shaped or equilateral triangular pile, $c_{g}=1.05$; for square pile, $c_{g}=1.13$ ). Under the above conditions, the compression deformation analysis method of reinforced section and unreinforced section of composite foundation is discussed.

\subsection{Compression Deformation Analysis of Reinforced Section.} In view of the characteristics and deformation characteristics of stone column, this paper adopts the iterative method of subcascade generation for compression deformation analysis. Now, the reinforced section is divided into $M$ microsegment units, the length of the reinforced section is $l_{0}$, and then the thickness of the $i$ microsegment unit $\Delta H_{i}$ is

$$
\Delta H_{i}=\frac{l_{0}}{M}
$$

The microsegment unit of pile body $i$-th of the stiffened section was taken for analysis, as shown in Figure 3. According to the basic assumption, the pile deformation is uniform and the volume remains the same before and after deformation. At the same time, it can be obtained by ignoring the high-order trace:

$$
a \Delta h_{i}=2 \Delta H_{i} \Delta r_{i},
$$

where $\Delta h_{i}$ and $\Delta r_{i}$ are the vertical and radial deformations of the $i$-th pile microsegment element, respectively.

Based on the coordinated and continuous deformation of pile and soil, it can be known that the swelling amount of pile body should be equal to the shrinkage amount of soil around the pile; that is, the mean circumjacent stress $\bar{\sigma}_{\theta p i}$ of the microsegment element body is equal to the mean radial stress $\bar{\sigma}_{r p i}$.

According to Hookie's law in spatial problems, it can be concluded that 

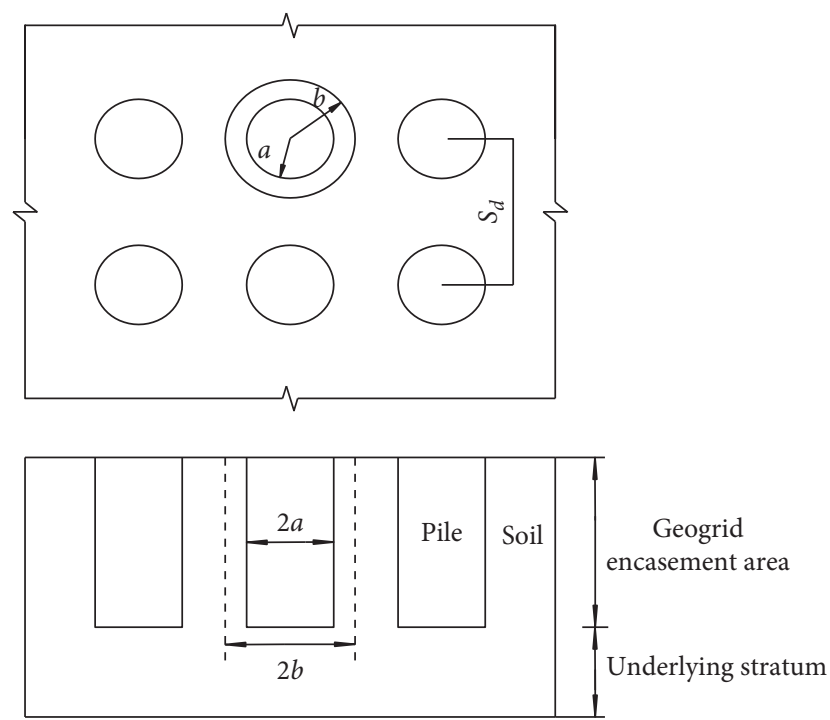

FIGURE 2: The unit of pile and soil.

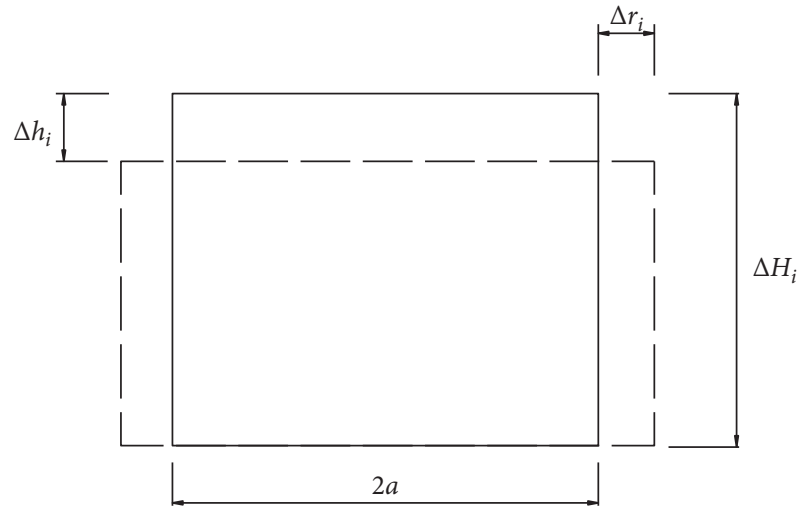

Figure 3: Deformation of the $i$-th microelement of pile.

$\varepsilon_{z p i}=\frac{\Delta h_{i}}{\Delta H_{i}}=\frac{1}{E_{p}}\left[\bar{\sigma}_{z p i}-\mu_{p}\left(\bar{\sigma}_{r p i}+\bar{\sigma}_{\theta p i}\right)\right]=\frac{1}{E_{p}}\left(\bar{\sigma}_{z p i}-2 \mu_{p} \bar{\sigma}_{r p i}\right)$,

$\varepsilon_{r p i}=\frac{\Delta r_{i}}{a}=\frac{1}{E_{p}}\left[\bar{\sigma}_{r p i}-\mu_{p}\left(\bar{\sigma}_{z p i}+\bar{\sigma}_{\theta p i}\right)\right]=\frac{1}{E_{p}}\left[\left(1-\mu_{p}\right) \bar{\sigma}_{r p i}-\mu_{p} \bar{\sigma}_{z p i}\right]$,

where $\varepsilon_{r p i}$ and $\varepsilon_{z p i}$ are the radial and vertical strains of the $i$ th microsegment element of pile body, respectively; $E_{p}$ is the compression modulus of pile body; $\mu_{p}$ is Poisson's ratio of the pile; and $\bar{\sigma}_{z p i}$ is the average vertical additional stress of the $i$-th pile microsegment element, and the average value of the additional stress at the bottom and top of the element can be taken as

$$
\bar{\sigma}_{z p i}=\frac{\left(\sigma_{z p i}+\sigma_{z p(i-1)}\right)}{2} .
$$

From equations (7) and (8), the vertical and radial deformation of the $i$-th pile element microsegment element can be obtained as

$$
\begin{aligned}
& \Delta h_{i}=\frac{\Delta H_{i}}{E_{p}}\left(\bar{\sigma}_{z p i}-2 \mu_{p} \bar{\sigma}_{r p i}\right), \\
& \Delta r_{i}=\frac{a}{E_{p}}\left[\left(1-\mu_{p}\right) \bar{\sigma}_{r p i}-\mu_{p} \bar{\sigma}_{z p i}\right] .
\end{aligned}
$$

Substituting equation (9) into equations (10) and (11), the additional stress $\sigma_{z p i}$ on the bottom of the pile microsegment unit is

$$
\sigma_{z p i}=A_{i} \Delta h_{i}+B_{i} \Delta r_{i}-\sigma_{z p(i-1)}
$$

where $A_{i}$ and $B_{i}$ are calculating parameters, $A_{i}=$ $\left(2 E_{p} / \Delta H_{i}\right)\left(1+\left(2 \mu_{p}^{2} / 1-\mu_{p}-2 \mu_{p}^{2}\right)\right), \quad B_{i}=4 E_{p} \mu_{p} /\left(1-\mu_{p}-\right.$ $\left.2 \mu_{p}^{2}\right) a$.

Take the $i$-th pile microsegment unit for force analysis, as shown in Figure 4, and from the vertical static balance of the pile, we can get

$$
\begin{aligned}
\pi(a & \left.+\Delta r_{(i-1)}\right)^{2} \sigma_{z p(i-1)}+2 \pi\left(a+\Delta r_{i}\right)\left(\Delta H_{i}-\Delta h_{i}\right) \tau_{i} \\
& =\pi\left(a+\Delta r_{i}\right)^{2} \sigma_{z p i} .
\end{aligned}
$$

In the formula, $\tau_{\mathrm{i}}$ is the average frictional force on the pile side of the $i$-th pile microsection unit. From equation (6), we can see that $\Delta r_{\mathrm{i}}$ is a function of $\Delta h_{\mathrm{i}}$, and we can make $\Delta r_{i}=f_{1}\left(\Delta h_{\mathrm{i}}\right)$; substituting $\Delta r_{\mathrm{i}}$ for equation (12), we can see that $\sigma_{z p i}$ is a function of $\Delta h_{\mathrm{i}}$, so that $\sigma_{z p i}=f_{2}\left(\Delta h_{\mathrm{i}}\right)$; equation (13) can obtain another functional relationship between $\sigma_{z p i}$ and $\Delta h_{\mathrm{i}}$, and $\sigma_{z p i}=f_{3}\left(\Delta h_{\mathrm{i}}\right)$.

Simultaneously, equations (12) and (13) can be used to obtain a univariate quadratic equation about $\Delta h_{\mathrm{i}}$; that is,

$$
F_{1 i} \Delta h_{i}^{2}+F_{2 i} \Delta h_{i}+F_{3 i}=0,
$$

where $F_{1 i}, F_{2 i}$, and $F_{3 i}$ are the calculation parameters of the $i$ th pile microsegment unit, $F_{1 i}=\left(a \tau_{i} / \Delta H_{i}\right)+\left(a^{2} \sigma_{z p i} / 4 \Delta H_{i}^{2}\right)$, $F_{2 i}=a \tau_{i}+\left(a^{2} \sigma_{z p i} / \Delta H_{i}\right)-a^{2} A_{i}-\left(a^{3} B_{i} / 2 \Delta H_{i}\right), \quad F_{3 i}=$ $2 a^{2} \sigma_{z p i}-2 a \tau_{i} \Delta H_{i}$.

$\Delta h_{\mathrm{i}}$ can be obtained from equation (14):

$$
\begin{aligned}
\Delta h_{i} & =\frac{-F_{2 i}+\sqrt{F_{2 i}^{2}-4 F_{1 i} F_{3 i}}}{2 F_{1 i}}, \\
\tau_{i} & =c_{a}+k_{0} p_{s z i} \tan \varphi_{a},
\end{aligned}
$$

where $c_{a}$ is the cohesion between piles and soil; $\varphi_{a}$ is the friction angle at the pile-soil interface; $p_{s z i}$ is the vertical additional stress of soil around the pile at the depth $z_{i}$ in the middle of the microsegment element of the $i$-th pile; and $k_{0}$ is the static earth pressure coefficient of soil around the pile. Because the soil around the pile has a certain shear strength, it is impossible to transfer excessive shear stress, so the pile lateral friction resistance is related to the soil's shear strength and is $\tau$ finite value. It can be considered that the pile lateral friction resistance does not exceed the soil's shear strength $\tau$, and the pile lateral friction resistance of the whole reinforced section is

$$
\tau_{z}=c_{a}+k_{0} p_{s z} \tan \varphi_{a} \leq \tau
$$




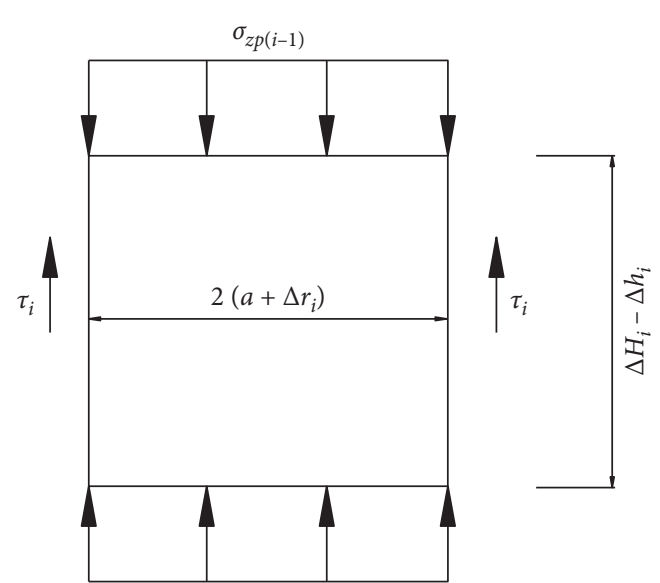

FIGURE 4: Stress analysis of the $i$-th microelement of pile.

\subsection{Compression Deformation Analysis of Unreinforced} Section. Similar to the above method, the unreinforced segment is divided into $N$ pile-soil microsegment units, and then the thickness of the $j$-th pile-soil microsegment unit $\Delta H_{\mathrm{j}}$ is

$$
\Delta H_{j}=\frac{l_{1}}{N} .
$$

From the above analysis, it can be seen that the impact of vertical deformation and radial deformation should be taken into account in calculating the compression deformation of nonstiffened segment as well as that of stiffened segment, but the relative slip of pile and soil should be ignored in nonstiffened segment and analyzed according to the pile-soil element.

Therefore, the compression deformation of nonstiffened segment can be analyzed by using the compression deformation method of stiffened segment. The $j$-th pile and soil element was taken for force analysis, as shown in Figure 5.
Considering the symmetry of pile-soil microsegment element and the stress coordination at the boundary of pilesoil element, the vertical stress at the boundary of pile-soil microsegment element $\tau_{j}=0$, and then the vertical static equilibrium of pile-soil microsegment element can be obtained as follows:

$$
\begin{gathered}
\pi\left(a+\Delta r_{(j-1)}\right)^{2} \sigma_{z p(j-1)}+\pi\left[b^{2}-\left(a+\Delta r_{(j-1)}\right)^{2}\right] \sigma_{z s(j-1)} \\
=\pi\left(a+\Delta r_{j}\right)^{2} \sigma_{z p j}+\pi\left[b^{2}-\left(a+\Delta r_{j}\right)^{2}\right] \sigma_{z s j},
\end{gathered}
$$

where $\Delta r_{(j-\mathrm{i})}$ and $\Delta r_{j}$ are, respectively, the radial deformations of the $(j-1)$ th and $j$-th micropile soil elements; $\sigma_{z p(j-i)}$ and $\sigma_{z p j}$ are the $(j-1)$ th and $j$-th micropile soil element vertical stress at the bottom of the element pile: $\sigma_{\mathrm{zs}(j-1)}$ and $\sigma_{z s j}$ are the vertical stress at the bottom of the $(j-1)$ th and $j$ th microelement soil element, and $\left.\sigma_{z s(j-}{ }{ }_{i}\right)=\sigma_{z p(j-\mathrm{i})} / n_{(j-\mathrm{i})}$, $\sigma_{z s j}=\sigma_{z p j} / n_{j}$, where $n_{(j-\mathrm{i})}$ and $n_{j}$ are the pile-soil stress ratios at the bottom of the $(j-1)$ th and $j$-th pile-soil units, respectively.

According to the reinforced section of compression deformation calculation, it is a cubic equation of one variable $\Delta h_{j}$ as follows:

$$
\lambda_{3 j} \cdot \Delta h_{j}^{3}+\lambda_{2 j} \cdot \Delta h_{j}^{2}+\lambda_{1 j} \Delta h_{j}=\lambda_{j}
$$

where $\lambda_{j}, \lambda_{1 j}, \lambda_{2 j}, \quad$ and $\lambda_{3 j}$ are parameters, $\lambda_{j}=$ $\left[n_{j}\left(a+\Delta r_{(j-1)}\right)^{2}+b^{2}\right] \sigma_{z p(j-1)}+n_{j}\left[b^{2}-\left(a+\quad \Delta r_{(j-1)}\right)^{2}\right]$ $\sigma_{z s(j-1)}, \lambda_{1 j}=\left[b^{2}+\left(n_{j}-1\right) a^{2}\right]\left(F_{1 j}+\left(F_{2 j} a / 2 \Delta Z_{j}\right)\right)-\left(\left(n_{j}-\right.\right.$ 1) $\left.a^{2} \sigma_{z p(j-1)} / \Delta Z_{j}\right), \quad \lambda_{2 j}=\left(\left(n_{j}-1\right) a^{2} / \Delta Z_{j}\right)\left(F_{1 j}+\left(\lambda_{2 j} a / 2 \Delta\right.\right.$ $\left.\left.Z_{j}\right)-\left(\sigma_{z p(j-1)} / 4 \Delta Z_{j}\right)\right), \lambda_{3 j}=\left(\left(n_{j}-1\right) a^{2} / 4 \Delta Z_{j}^{2}\right)\left(F_{1 j}+\left(F_{2 j} a\right.\right.$ $\left.\left./ 2 \Delta Z_{j}\right)\right)$.

An analytical solution can be obtained from formula (19); that is,

$$
\begin{aligned}
& \lambda_{j}=\left[n_{j}\left(a+\Delta r_{(j-1)}\right)^{2}+b^{2}\right] \sigma_{z p(j-1)}+n_{j}\left[b^{2}-\left(a+\Delta r_{(j-1)}\right)^{2}\right] \sigma_{z s(j-1)}, \\
& \lambda_{1 j}=\left[b^{2}+\left(n_{j}-1\right) a^{2}\right]\left(F_{1 j}+\frac{F_{2 j} a}{2 \Delta Z_{j}}\right)-\frac{\left(n_{j}-1\right) a^{2} \sigma_{z p(j-1)}}{\Delta Z_{j}}, \\
& \lambda_{2 j}=\frac{\left(n_{j}-1\right) a^{2}}{\Delta Z_{j}}\left(F_{1 j}+\frac{\lambda_{2 j} a}{2 \Delta Z_{j}}-\frac{\sigma_{z p(j-1)}}{4 \Delta Z_{j}}\right), \\
& \lambda_{3 j}=\frac{\left(n_{j}-1\right) a^{2}}{4 \Delta Z_{j}^{2}\left(F_{1 j}+\frac{F_{2 j} a}{2 \Delta Z_{j}}\right)}, \\
& \Delta h_{j}=\sqrt[p]{-\frac{q_{j}}{2}+\sqrt{\left(\frac{q_{j}}{2}\right)^{2}+\left(\frac{p_{j}}{3}\right)^{3}}+\sqrt{-\frac{q_{j}}{2}-\sqrt{\left(\frac{q_{j}}{2}\right)^{2}+\left(\frac{p_{j}}{3}\right)^{3}}}-\frac{\lambda_{2 j}}{3 \lambda_{3 j}}}
\end{aligned}
$$




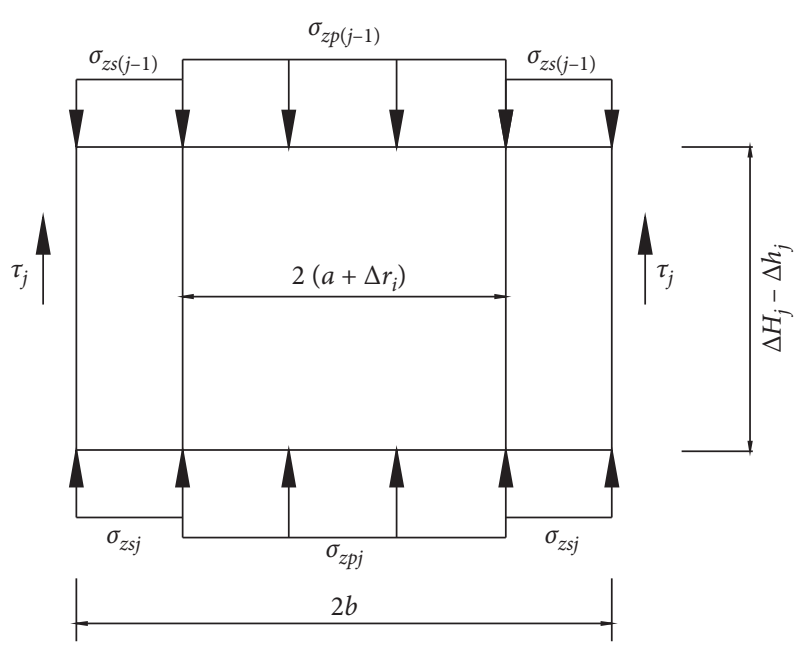

FIgURE 5: Stress analysis of the $j$-th pile-soil microelement in the unreinforced section.

where $q_{j}$ and $p_{j}$ are parameters, $q_{j}=\left(\lambda_{2 j}\left(2 \lambda_{2 j}^{2}-9 \lambda_{1 j} \lambda_{3 j}\right)-\right.$ $\left.27 \lambda_{j} \lambda_{3 j}^{2}\right) /\left(27 \lambda_{3 j}^{3}\right), p_{j}=\left(3 \lambda_{1 j} \lambda_{3 j}-\lambda_{2 j}^{2}\right) /\left(3 \lambda_{3 j}^{2}\right)$.

3.4. Calculation of Compressive Deformation in Reinforced Section. From the above analysis, it is known that the compression deformation amount $S_{11}$ of the reinforced section in the reinforced area is $S_{11}=\sum_{i=1}^{M} \Delta h_{i}$, and the compression deformation amount $S_{12}$ of the unreinforced section in the reinforced area is $S_{12}=\sum_{j=1}^{N} \Delta h_{j}$. The calculation formula of the compression deformation amount of the entire reinforced area is $S_{1}$ :

$$
S_{1}=S_{11}+S_{12}=\sum_{i=1}^{M} \Delta h_{i}+\sum_{j=1}^{N} \Delta h_{j} .
$$

3.5. Determination of Related Calculating Parameters. The abovementioned analysis method for the settlement of the reinforced stone column reinforcement zone has been established. From equations (15) and (20), it can be known that the compression deformation $S_{1}$ in the reinforced section is related to the following parameters:

$$
S_{1}=F\left(a, b, \Delta H_{i}, \Delta H_{j}, \Delta r_{i}, \Delta r_{j}, \sigma_{z p i}, \sigma_{z s i}, \sigma_{z p j}, \sigma_{z s j}, n_{j}\right),
$$

where $a, b, \Delta H_{i}$, and $\Delta H_{j}$ are geometric parameters for composite foundation, which can be determined by the engineering condition and the calculation precision; $\Delta r_{i}$, $\sigma_{z p i}, \sigma_{z s i}, \Delta r_{j}, \sigma_{z p j}, \sigma_{z s j}$, and $n_{j}$ are stress-strain parameters, which need to be calculated and determined. The determination process of parameters is as follows.

Step 1. Determining $\Delta r_{i}$ and $\Delta r_{j}$. In the reinforced section, $\Delta r_{i}$ is the radial deformation of the top of the $(i+1)$-th pile microsegment unit (that is the bottom of the $i$-th pile microsegment unit). Since the compression deformation analysis of the pile is recursive from top to bottom, the $i$-th element is calculated from the $(i-1)$-th element, and $\Delta r_{i}$ can be obtained by analogy from the radial initial deformation $\Delta r_{0}$. Since the first microsegment element of the pile body is close to the bottom of the foundation or cushion, which has a greater constraint on the pile, $\Delta r_{0}=0$ is assumed in order to simplify the calculation. $\Delta r_{(j-1)}$ can also be obtained by using the same method in the unreinforced section, where the first microelement of the pile body is the radial deformation of the interface between the reinforced section and the unreinforced section. The radial deformation of the top surface of the first pile-soil element is equal to the one of the bottom surfaces of the adjacent pile-soil element in the unreinforced section, that is, $\left.\Delta r_{j}\right|_{j=0}=\left.\Delta r_{i}\right|_{i=M}$.

Step 2. Determining $\sigma_{z p}$ and $\sigma_{z s}$. In the reinforced section, $\sigma_{\mathrm{zp}(i-1)}$ is the vertical additional stress of the top surface of the $i$-th pile-soil unit, and $\sigma_{\mathrm{zs}(i-1)}$ is the vertical additional stress of the surrounding soil. Likewise, $\Delta r_{(i-1)}, \sigma_{z p(i-1)}$ and $\sigma_{z s(i-1)}$ can be determined by the initial condition, that is, $\sigma_{z p 0}$ and $\sigma_{z s 0}$ of the first pile-soil unit, which are calculated as follows:

$$
\begin{aligned}
\sigma_{z s 0} & =p_{s}=\frac{p}{[1+m(n-1)]}, \\
\sigma_{z p 0} & =p_{p}=n p_{s},
\end{aligned}
$$

where $p_{p}$ and $p_{s}$ are the vertical additional stresses on the top of the pile and surrounding soil; $p$ is the vertical pressure on the top of the composite foundation; $m$ is the area replacement rate; and $n$ is the stress ratio of the pile and soil, which can be calculated by the following formula (14) when there is no measured value:

$$
n=\frac{E_{p}}{2 k_{p} E_{s} \ln (b / a)}+\frac{k_{s}}{k_{p}},
$$

where $E_{p}$ is the compression modulus of the pile, $E_{s}$ is the compression modulus of the soil, $k_{p}$ is the coefficient of lateral pressure of pile, and $k_{s}$ is the coefficient of lateral pressure of the soil around the pile.

In the unreinforced section, considering the continuity of stress, the vertical additional stress of the pile and soil at the top of the unreinforced section is equal to the one at the bottom of the reinforced section, that is,

$$
\begin{gathered}
\left.\sigma_{z p j}\right|_{j=0}=\left.\sigma_{z p i}\right|_{i=M}, \\
\left.\sigma_{z s j}\right|_{j=0}=\left.\sigma_{z s i}\right|_{i=M} .
\end{gathered}
$$

Step 3. Determining the pile-soil stress ratio $n_{j}$ of the element. Considering that the stone column is divided into many units and the thickness is small, the pile-soil stress ratio varies little in a pile-soil unit. To simplify the calculation, it can be assumed that the pile-soil stress ratio of the unit remains unchanged, that is,

$$
n_{j}=\frac{\sigma_{z p j}}{\sigma_{z s j}} \approx \frac{\sigma_{z p(j-1)}}{\sigma_{z s(j-1)}} \approx \frac{\sigma_{z p 0}}{\sigma_{z s 0}} .
$$




\section{Engineering Case Analysis}

In order to verify the rationality and feasibility of the above calculation method for the composite foundation of the reinforced stone column composite foundation, an engineering example is cited for analysis.

4.1. Case 1. When the length of the reinforced section of the reinforced stone column is zero, the settlement calculation method of the composite foundation of the reinforced stone column can be transformed into the settlement calculation method of the ordinary stone column composite foundation. In order to verify the versatility and rationality of the above calculation method for the settlement of the reinforced stone column composite foundation, an example of common stone column composite foundation engineering is first introduced for analysis.

Taking a water conservancy project in [15] as an example, a sluice is planned to be built on silt and silty sand foundation, the surface layer is $2.0 \sim 4.5 \mathrm{~m}$ which is silt, and the bearing capacity of the foundation is $100 \mathrm{kPa}$; below the silt is livery-grey silt sand with a foundation bearing capacity of $80 \mathrm{kPa}$. The groundwater is $2 \mathrm{~m}$ below the ground. The foundation of the lock chamber is reinforced with vibrating stone piles. The literature [15] used the finite element method to analyze the foundation strengthened by crushed stone piles. The simulated pile diameter was $1 \mathrm{~m}$, the pile length was $11 \mathrm{~m}$, and the total calculated depth of the foundation was $12 \mathrm{~m}$. For other specific parameters, see the literature. When the upper load is $150 \mathrm{kPa}$, the settlement of the composite foundation is $4.76 \mathrm{~cm}$. The above data are used to calculate the settlement of the project using the method in this paper. The length of the reinforced section of the composite foundation is set to zero, the unreinforced section is equally divided into 50 units, and the calculated $S_{12}=3.97 \mathrm{~cm}$; the lower layer is calculated using the layered sum method to calculate $S_{2}=0.87 \mathrm{~cm}$; the total settlement of the project is $S=4.84 \mathrm{~cm}$, which is close to the calculation results of the finite element method, which shows that the method in this paper is reasonable and can be degraded to one of the ordinary composite foundations reinforced by stone columns.

4.2. Case 2. This project is a ramp of a highway interchange in Sichuan, which uses geogrid encasement, stone column, and sand cushion to reinforce the roadbed [16]. The parameters of the composite foundation are as follows: the thickness of cushion is $h=10 \mathrm{~cm}$, the compression modulus of cushion is $E_{c}=20 \mathrm{MPa}$, the diameter of stone column is $d=0.6 \mathrm{~m}$, the length of pile is $L=6 \mathrm{~m}$, the arrangement of piles is like a plum blossom, pile spacing is $S_{d}=2 \mathrm{~m}$, internal friction angle of stone is $\varphi_{p}=38^{\circ}$, and Poisson's ratio is $\mu_{p}=0.35$, the length of geogrid encasement is $l_{0}=2 \mathrm{~m}$, and the compression modulus of reinforced section is $E_{p}=100 \mathrm{MPa}$ and $E_{p}=20 \mathrm{MPa}$ in the unreinforced section. The distribution of pile and soil layers is shown in Figure 6, and the calculating parameters are shown in Table 1. A uniformly distributed load $p=120 \mathrm{kPa}$ is applied to the

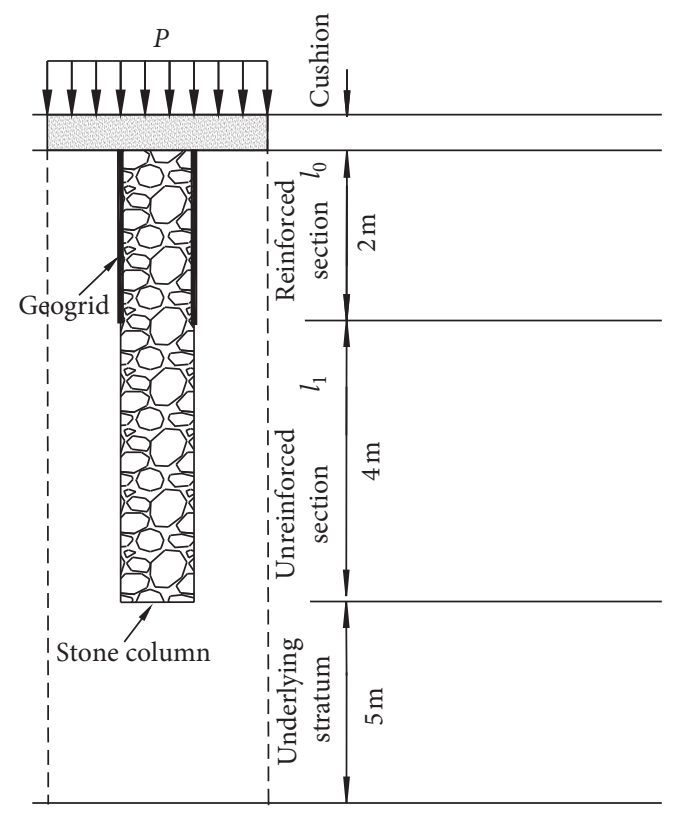

FIGURE 6: Distribution of pile and surrounding soil.

treated subgrade surface. The measured pile-soil stress ratio is $n=3.12$, and the subgrade settlement is $S=11 \mathrm{~cm}$.

The settlement calculation of the subgrade project is carried out by using the above data in Table 1 and the method in this paper. The specific process is as follows:

(a) Calculating the replacement rate of the composite foundation area $m=8.2 \%$ and the pile-soil stress ratio $n=3.12$. From formulas (23) and (24), the load on the pile-soil top surface is $\sigma_{z p 0}=350.84 \mathrm{kPa}$ and $\sigma_{z s 0}=112.45 \mathrm{kPa}$.

(b) Calculating $S_{11}$ : the reinforced section is divided into 10 element bodies, and the element body is analyzed and calculated one by one from top to bottom. Finally, the compression deformation of the reinforced section is $S_{11}=2.547 \mathrm{~cm}$.

(c) Calculating $S_{12}$ : the unreinforced section is divided into 20 element bodies, and the element body is analyzed and calculated one by one from top to bottom. The final compression deformation of the unreinforced section is $S_{12}=8.251 \mathrm{~cm}$.

(d) The compression deformation of the underlying stratum: using the layer-wise summation method to obtain the settlement $S_{2}=1.072 \mathrm{~cm}$.

(e) According to formula (3), it can be known that the total deformation of composite foundation $S=11.87 \mathrm{~cm}$.

In order to facilitate comparative analysis, other methods are used to calculate the settlement in Case 2, and the results are shown in Table 2. It can be seen from Table 2 that the calculated results of this method and other methods are close to the measured values. The calculated results of this method are larger than those of other methods. Considering that theoretical derivation is generally the final settlement of 
TABLE 1: Calculating parameter.

\begin{tabular}{lccccc}
\hline Section & Soil type & $\varphi\left(^{\circ}\right)$ & $E_{\mathrm{s}}(\mathrm{MPa})$ & $\rho_{s}\left(\mathrm{~g} / \mathrm{cm}^{3}\right)$ & $\mu_{s}$ \\
\hline Reinforced section & Filled soil & 31 & 6 & 1.70 & 0.4 \\
Unreinforced section & Weak soil & 5.8 & 2.74 & 1.75 & 14.9 \\
Underlying stratum & Pebble soil & 26 & 50 & 1.60 & 0.45 \\
\hline
\end{tabular}

TABLE 2: Calculation results of different methods.

\begin{tabular}{lccc}
\hline Method & Calculated value $(\mathrm{cm})$ & Measured values $(\mathrm{cm})$ & Relative error $(\%)$ \\
\hline Method from the literature [10] & 10.8 & 11.0 & -1.82 \\
Finite element method [16] & 10.9 & 11.0 & -0.91 \\
Proposed method & 11.87 & 11.0 & +7.90 \\
\hline
\end{tabular}

foundation, while the measured value is the settlement at a certain time, and the value is generally less than the final settlement, the method in this paper is more in line with the actual situation and avoids the defect that the analysis results of other methods are too dangerous. Therefore, the method used in this paper to calculate the settlement of composite foundation is in good agreement with the actual situation. However, it is undeniable that there still exists certain calculation error of the method in this paper, the main reason is the research object is limited to by high tensile bidirectional geogrid on top of the stone column within the following $2 \sim 3$ times the depth of the pile diameter fan sleeve formed by confining hoop reinforcement stone column composite foundation, and the formula is derived using the continuous homogeneous medium assumption and the basic principle of mechanics of elasticity. We assume unit cell of constant stress ratio of pile-soil and add composite foundation reinforced by geogrid-encased stone column settlement and the actual engineering by the combination of many factors, such as stone column itself has large discreteness, and when the upper load is bigger, grille sleeve reinforced section will appear larger nonlinear deformation. The stress of pile and soil will increase with load-increasing.

\section{Conclusions}

Based on the analysis of bearing and deformation mechanism of composite foundation reinforced by geogridencased stone columns, the settlement calculation method of this type of composite foundation is discussed. Theoretical analysis shows that the geogrid encasement effectively limits the radial deformation of the upper half of the stone column, making the half of the stone column body flexible or semirigid. The load transfer capacity of the stone column is stronger, and the deformation is more. Therefore, considering the relative slip of the pile and soil in the reinforced section and the coordinated characteristics of vertical and radial deformation of the pile and soil in the unreinforced section, the composite foundation reinforced by geogrid-encased stone column is divided into the reinforced section, unreinforced section, and underlying stratum.

The settlement calculation model was established in the three sections of the horizontal layer, which accorded with the bearing and deformation characteristics of composite foundation reinforced by the geogrid-encased stone column. The analysis of engineering examples shows that the proposed method for calculating the settlement of the composite foundation of the geogrid-encased stone column composite foundation has good engineering accuracy and overcomes the shortcomings of the analysis results of the existing analysis methods, which are biased to danger, and it has good rationality and feasibility.

In addition, the settlement calculation method of geogridencased stone column composite foundation proposed in this paper is mainly aimed at the reinforced gravel formed by the sleeve hoop within the depth range of $2 \sim 3$ times of the pile diameter below the top of the stone column using a two-way high-strength geogrid reinforcement, and the theoretical derivation uses the assumption of continuous homogeneous medium and the basic principles of elastic mechanics and the calculation assumption that the pile-soil stress ratio of the unit body is constant. In practice, the settlement of composite foundation reinforced by geogrid-encased stone column is affected by many factors such as the stiffness of stone column [17], the failure model of stone column [18], and the consolidation state of soil [19]. In addition, the method proposed in this paper still cannot consider the plastic state of pile and soil and needs to be further improved.

\section{Nomenclature}

List of symbols

$S$ : $\quad$ Settlement of geogrid-encased stone column composite foundation

$S_{1}$ : Amount of compression in reinforcement area

$S_{2}$ : The amount of compression in the underlying strata

$S_{11}$ : Amount of compression in stiffened section

$S_{12}$ : Amount of compression in nonstiffened segment

$a$ : The radius of pile body

$b$ : $\quad$ Pile and soil element body radius

$d_{e}$ : The diameter of the element body

$S_{d}: \quad$ The center distance between piles

$c_{g}$ : The influence coefficient of pile layout

$l_{0}$ : The length of the reinforced section

$\triangle H_{\mathrm{i}}$ : The thickness of the $i$-th microsegment element

$\triangle h_{\mathrm{i}}$ : The vertical deformation of the $i$-th pile microsegment element 
$\triangle r_{\mathrm{i}}: \quad$ The radial deformation of the microsegment element of the $i$ th pile body

$\bar{\sigma}_{\theta p i}: \quad$ Mean circumferential stress

$\bar{\sigma}_{r p i}: \quad$ Mean radial stress

$\varepsilon_{r p i}: \quad$ Radial strain of the $i$-th pile microsegment element

$\varepsilon_{z p i}: \quad$ The vertical strain of the $i$-th pile microsegment element

$E_{p}: \quad$ The compression modulus of pile body

$E_{s}$ : The compression modulus of the soil

$\mu_{p}: \quad$ Poisson's ratio of the pile

$\bar{\sigma}_{z p i}: \quad$ The average vertical additional stress of the $i$-th pile microsegment element

$\tau_{\mathrm{i}}: \quad$ The average frictional force on the pile side of the $i-$ th pile microsection unit

$F_{1 i}: \quad$ The calculation parameters of the $i$-th pile microsegment unit

$F_{2 i}: \quad$ The calculation parameters of the $i$-th pile microsegment unit

$F_{3 i}: \quad$ The calculation parameters of the $i$-th pile microsegment unit

$c_{a}: \quad$ The cohesion between piles and soil

$\varphi_{a}: \quad$ The friction angle at the pile-soil interface

$p_{s z i}$ : The vertical additional stress of soil around the pile at the depth $z_{i}$ in the middle of the microsegment element of the $i$-th pile

$k_{0}$ : The static earth pressure coefficient of soil around the pile

$\tau: \quad$ The soil's shear strength

$\Delta H_{j}: \quad$ The thickness of the $j$-th pile-soil microsegment unit $\Delta H_{\mathrm{j}}$

$\Delta r_{(j-i)}:$ The radial deformations of the $(j-1)$ th micropile soil elements

$\Delta r_{j}: \quad$ The radial deformations of the $j$-th micropile soil elements

$\sigma_{z p(j-\mathrm{i})}$ : The $(j-1)$ th micropile soil element vertical stress at the bottom of the element pile

$\sigma_{z p j}: \quad$ The $j$-th micropile soil element vertical stress at the bottom of the element pile

$\sigma_{z s(j-1}$ : The vertical stress at the bottom of the $j$-th microelement soil element

$\sigma_{z s j}: \quad$ The vertical stress at the bottom of the $j$-th microelement soil element

$n_{(j-i)}: \quad$ The pile-soil stress ratios at the bottom of the $(j-1)$ th pile-soil units

$n_{j}$ : $\quad$ The pile-soil stress ratios at the bottom of the $j$-th pile-soil units

$\lambda_{j}: \quad$ The calculation parameter

$\lambda_{1 j}: \quad$ The calculation parameter

$\lambda_{3 j}: \quad$ The calculation parameter

$q_{j}: \quad$ The calculation parameter

$p_{j}: \quad$ The calculation parameter

$k_{p}$ : The coefficient of lateral pressure of pile

$k_{s}$ : The coefficient of lateral pressure of the soil around the pile.

\section{Data Availability}

The data used to support the findings of this study are available from the corresponding author upon request.

\section{Conflicts of Interest}

The authors declare that they have no conflicts of interest.

\section{Acknowledgments}

The work described in this paper was fully supported by these grants from the National Natural Science Foundation of China (award nos. 51778227, 51308208, and 41372303), the Provincial Natural Science Foundation of Hunan (award nos. 2015JJ3069 and 18C0311), the Youth Talent Plan Program of Hunan (award no. 2016RS3032), and the Postgraduate Scientific Research Innovation Project of Hunan Province (award no. CX20200992).

\section{References}

[1] B. Wang, F. Zhang, and B. Wang, "Development of stone column compound foundation and its application in hydraulic projects," Advances in Science and Technology of Water Resources, vol. 21, no. 4, pp. 56-58, 2001.

[2] F. Zhang, B. Wang, B. Wang et al., "Application of large grainsize stone columns to strengthening saturated super-soft ground," Journal of Hohai University (Natural Sciences), vol. 34, no. 4, pp. 430-434, 2006.

[3] X. Gong, Composite Foundation Theory and Engineering Application, China Building Industry Press, Beijing, China, 2007.

[4] Z. Zhou and Q. Zhang, "Analysis on the bearing capacity of geogrid reinforced stone-column," Chinese Journal of Geotechnical Engineering, vol. 19, no. 1, pp. 18-21, 1997.

[5] C. Chen and Q. Li, "Calculation of bearing capacity of geosynthetic-encased stone column based on cavity expansion theory," Journal of Hunan University (Natural Science), vol. 38, no. 10, pp. 7-12, 2011.

[6] C. Chen and $\mathrm{M}$. Wu, "Computational method for bearing capacity of upper geosynthetic-encased stone columns based on block limit equilibrium method," Chinese Journal of Geotechnical Engineering, vol. 35, no. 7, pp. 1253-1260, 2013.

[7] C. Wang, C. Chen, and Y. Zhao, "Upper-bound limit analysis of ultimate bearing capacity of upper geosynthetic-encased stone column," Rock and Soil Mechanics, vol. 36, no. 6, pp. 1801-1805, 2015.

[8] M. Zhao, Q. Chen, L. Zhang et al., "Calculation of bearing capacity of geosynthetic-encased stone columns," Journal of Highway and Transportation Research and Development, vol. 28, no. 8, pp. 7-12, 2011.

[9] M. Zhao, Z. Zhang, M. Liu et al., "Calculation of ultimate bearing capacity of composite foundation with geosynthetic encased stone columns," Hydrogeology \&Engineering Geology, vol. 41, no. 1, pp. 67-73, 2014.

[10] W. Cao and Z. Yang, "Method for analyzing settlement of reinforced-pile composite ground under flexible foundation," Chinese Journal of Geotechnical Engineering, vol. 34, no. 11, pp. 1997-2004, 2012.

[11] M. Wu and C. Chen, "Settlement computation of composite foundation of upper geosynthetic-encased stone column," China Science Paper, vol. 8, no. 11, pp. 1095-1099, 2013.

[12] X. Tan, L. J. Feng, and H. U. Zheng, "Failure modes and ultimate bearing capacity of the isolated stone column in soft soil," Bulletin of Engineering Geology and the Environment, no. 1, 2021. 
[13] F. R. Esameldin and N. Zalihe, "Behavior of geotextile encased single stone column in soft soils," Arabian Journal for Science and Engineering, vol. 45, no. 5, pp. 3877-3890, 2020.

[14] M. J. Gao, Experimental Study on Load-Bearing Characteristics of Tubular Grilled-Reinforced Stone Columns, Hohai University, Nanjing, China, 2008.

[15] W. Yu, F. Su, and X. Tang, "Finite element analysis on soft soil foundation reinforcement with stone column," Journal of Water Resources and Architectural Engineering, vol. 11, no. 5, pp. 114-117, 2013.

[16] B. Huang, Mechanism of GSPS Soft Base Reinforcement System and its Application in Chengdu Bypass Expressway, Southwest Jiaotong University, Chengdu, China, 2002.

[17] R. Cao, R. Yao, J. Meng, Q. Lin, H. Lin, and S. Li, "Failure mechanism of non-persistent jointed rock-like specimens under uniaxial loading: laboratory testing," International Journal of Rock Mechanics and Mining Sciences, vol. 132, Article ID 104341, 2020.

[18] R. Cao, R. Yao, and T. Hu, "Failure and mechanical behavior of transversely isotropic rock under compression-shear tests: laboratory testing and numerical simulation," Engineering Fracture Mechanics, vol. 241, Article ID 107389, 2021.

[19] R. Cao, C. Wang, R. Yao et al., "Effects of cyclic freeze-thaw treatments on the fracture characteristics of sandstone under different fracture modes: laboratory testing," Theoretical and Applied Fracture Mechanics, vol. 109, Article ID 102738, 2020. 